\title{
Elevated Intra-abdominal Pressure is a "Second-hit"
}

\author{
Adhish Basu
}

Published online: 12 January 2010

(C) Société Internationale de Chirurgie 2010

\section{Dear Sir,}

I read with interest the article entitled "Prospective study of intra-abdominal pressure following major elective abdominal surgery" by Scollay et al. [1]. The authors measured the intra-abdominal pressure (IAP) in 42 patients after elective laparotomy for various foregut and hepatopancreatobiliary procedures. Five patients (12\%) developed low grade intra-abdominal hypertension (IAH) [2]. There were no significant postoperative complications in four of these five patients. The authors concluded that "the routine measurement of IAP in the postoperative period is not warranted." This conclusion likely needs further clarification.

An elevated IAP reduces the blood flow to the abdominal viscera [3]. The reduction in visceral perfusion is objectively quantified in terms of the abdominal perfusion pressure (APP), which is measured by subtracting IAP from the mean systemic blood pressure (MBP) [4]. This reduced blood flow (i.e., reduced APP) may affect anastomotic integrity and lead to postoperative complications. However, mildly elevated IAP by itself may not reduce the APP to critical levels. Only when the MBP is lowered sufficiently (especially in critically ill patients) can IAH act as a "second-hit" to lower the APP further. This reduced visceral perfusion could then adversely affect the anastomosis and lead to postoperative complications [5].
A. Basu $(\bowtie)$

Department of Plastic Surgery, Postgraduate Institute of Medical Education and Research (PGIMER), Chandigarh, India
Moreover, absence of any significant complications attributable to IAH in this series of patients renders the study underpowered to make a case for abandoning IAP measurements in critically ill patients and patients who undergo major abdominal surgery.

\section{References}

1. Scollay JM, de Beaux I, Parks RW (2009) Prospective study of intra-abdominal pressure following major elective abdominal surgery. World J Surg 33:2372-2377

2. Malbrain ML, Cheatham ML, Kirkpatrick A, Sugrue M, Parr M, De Waele J et al (2006) Results from the international conference of experts on intra-abdominal hypertension and abdominal compartment syndrome. I. Definitions. Intensive Care Med 32:17221732 [Epub 12 Sep 2006]

3. Diebel LN, Dulchavsky SA, Wilson RF (1992) Effect of increased intra-abdominal pressure on mesenteric arterial and intestinal mucosal blood flow. J Trauma 33:45-49

4. Cheatham ML, White MW, Sagraves SG, Johnson JL, Block EF (2000) Abdominal perfusion pressure: a superior parameter in the assessment of intra-abdominal hypertension. J Trauma 49:621-626

5. Basu A, Pai DR (2008) Early elevation of intra-abdominal pressure after laparotomy for secondary peritonitis: a predictor of relaparotomy? World J Surg 32:1851-1856 